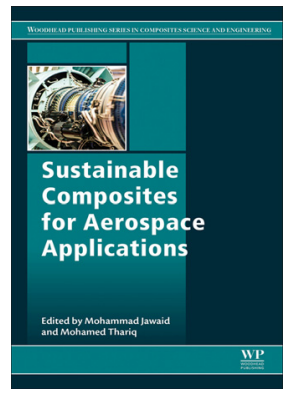

\section{Sustainable Composites for Aerospace Applications}

\section{Edited by M. Jawaid and M. Thariq \\ Woodhead Publishing, Langford Lane, Kidlington, Oxford, OX5 1GB, UK. 2018. xxiv; 364pp. Illustrated £190. ISBN \\ 978-0-08-102131-6.}

$\mathrm{T}$ The subject of sustainability in aerospace application of is a major importance to the sector. A step change in structural efficiency leading to sustainable levels of emissions is required if the industry is to meet the challenges required for clean future transport.

This book does little to address these challenges. Whilst it does contain some useful accounts of the performance of composites with natural fibres, it does not provide an examination of the vital areas relating to specific strength, damage tolerance and the influence of advanced materials on weight reduction, reduced maintenance, extended life and end of life recycling.
Civil transport aircraft use carbon fibre reinforced plastic because it outperforms aluminium; particularly when laminates are relatively thin and prone to buckling. This trade-off is of paramount importance to the industry, which generates an increasing proportion of global emissions. I would have expected a book with this title to address and describe these challenges within a scientific framework.

The book is made up of chapters from a wide collection of researchers, covering standard areas such as materials selection, polymers in aerospace, manufacturing techniques, impact damage, repair, machining and inspection/NDT. It also includes chapters on biocomposites, natural-hybrid composites, biomass filler-reinforced polymers and the application of some of these materials to secondary structure. However, it would be useful to evaluate the implications of the use of these materials in the wider system; the impact that the use of these composites would have on the industry as a whole is missing.

Similarly, although there are studies of a variety of composites, the performance indicators associated with them are not backed up with a rigorous methodology. For example, how are the authors determining sustainability? On what merit? Is it embodied greenhouse gasses or energy? This is not clear. Although the use of 'natural' materials is often considered inherently sustainable, often when examined rigorously using a life cyclebased assessment, it becomes clear that there are significant impacts. These are not identified through a robust analysis. Furthermore, the standard of presentation is not high. 
For all these reasons, I do not recommend that readers, looking for a rigorous treatment of sustainability in aerospace composites, purchase this book.

Professor Richard Butler, MRAeS

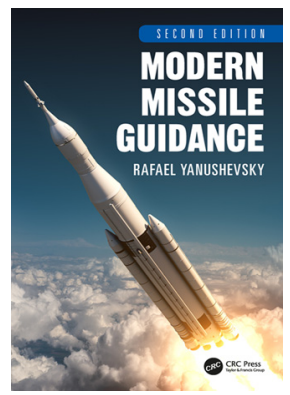

\section{Modern Missile Guidance - Second edition}

\section{R. Yanushevsky}

CRC Press, Taylor \& Francis Group, 6000 Broken Sound Parkway NW, Suite 300, Boca Raton, FL 33487-2742, USA. 2018.

Distributed by Taylor \& Francis Group, 2 Park Square, Milton Park, Abingdon, OX14 4RN, UK. xv; 325pp. Illustrated £140. (20\% discount available to RAeS members via www.crcpress.com using AKQ07 promotion code). ISBN 978-0-8153-8486-1.

primary aim of the author is to
present missile guidance law design
'from the point of view of control theory'.

Chapters 1-3 act as an introduction to guidance laws based around Proportional Navigation (PN) and, in particular, includes their analysis by the method of Adjoints. Adjoint analysis provides the sensitivity of miss distance to initial conditions as a function of time-to-go.

The main theme of the book is developed in Chapters 4, 6 and 7. Chapter 4 sets out the basics of frequency domain analysis. Analytical expressions are developed 